\title{
Specific Amino Acid (L-Arginine) Requirement for the Microbiostatic Activity of Murine Macrophages
}

\author{
Donald L. Granger, John B. Hibbs, Jr.," John R. Perfect, and David T. Durack \\ Division of Infectious Diseases, Department of Medicine, Duke University Medical Center, Durham, North Carolina 27710; and \\ *Infectious Diseases, Veterans Administration Medical Center and University of Utah Medical Center, Salt Lake City, Utah 84148
}

\section{Abstract}

The microbiostatic action of macrophages was studied in vitro employing peritoneal cytotoxic macrophages (CM) from mice acting against Cryptococcus neoformans cultured in Dulbecco's medium with $10 \%$ dialyzed fetal bovine serum. Fungistasis was measured using electronic particle counting after lysis of macrophages with detergent.

Macrophage fungistasis failed in medium lacking only Larginine. Complete fungistasis was restored by L-arginine; restoration was concentration dependent, maximal at $200 \mu \mathrm{M}$. Deletion of all other essential amino acids did not abrogate fungistasis provided that L-arginine was present. Of twenty guanido compounds, including D-arginine, only three (L-arginine, L-homoarginine, and L-arginine methylester) supported fungistasis. Known activators or mediators of macrophage cytotoxicity (endotoxin, interferon gamma, tumor necrosis factor) did not replace L-arginine for CM-mediated fungistasis. The guanido analogue $\boldsymbol{N}^{\mathbf{G}}$-monomethyl-L-arginine was a potent competitive inhibitor of $\mathrm{CM}$-mediated fungistasis giving $50 \%$ inhibition at an inhibitor/L-arginine ratio of 1:27. Although $\mathrm{CM}$ completely blocked fungal reproduction via an $\mathrm{L}$ arginine-dependent mechanism, the majority of the dormant fungi remained viable. Thus, this mechanism is viewed as a microbiostatic process similar or identical to the tumoristatic effect of macrophages. This suggests the production of a broad spectrum biostatic metabolite(s) upon consumption of $\mathbf{L}$-arginine by cytotoxic macrophages.

\section{Introduction}

Macrophages can kill or inhibit the replication of many facultative and obligate intracellular microorganisms. Although numerous studies have focused on the oxygen-dependent NADPH oxidase killing reaction of macrophages, relatively little is known about the mechanism by which macrophages inhibit microbial reproduction. This point may be relevant to a group of bacterial, protozoal, and fungal infections in which

This work was presented in abstract form at the American Association of Physicians/American Society for Clinical Investigation/American Federation for Clinical Research national meeting, San Diego, CA, 1 May 1987.

Address reprint requests to Dr. Granger, P.O. Box 2968, Duke University Medical Center, Durham, NC 27710.

Received for publication 17 April 1987 and in revised form 7 OCtober 1987

J. Clin. Invest.

(c) The American Society for Clinical Investigation, Inc.

0021-9738/88/04/1129/08 $\$ 2.00$

Volume 81, April 1988, 1129-1136 dormant but viable microorganisms persist in tissues for long periods followed by reactivation of microbial replication and concomitant disease upon iatrogenic or acquired cellular immunodeficiency states.

We have characterized a cell culture system employing activated murine peritoneal macrophages (cytotoxic macrophages, CM) ${ }^{1}$ challenged with Cryptococcus neoformans (1). Under appropriate conditions fungal cell replication is inhibited by $\mathrm{CM}$, beginning at 3-6 $\mathrm{h}$ after contact between phagocytes and microbes. Fungistasis lasts for $20-40 \mathrm{~h}$ and occurs with or without phagocytosis, provided target and effector cells are in close contact. Most fungal cells remain viable because they form colonies when removed from CM. Requirements for the fungistatic action of $\mathrm{CM}$ have been published $(1,2)$.

Recently Hibbs et al. reported that CM-mediated injury to neoplastic cells was dependent on the metabolism of L-arginine through a deimination pathway producing nitrite and citrulline $(3,4)$. The inhibitory action of $\mathrm{CM}$ on $C$. neoformans provides an ideal experimental system for testing the potential importance of this pathway for microbiostasis because the fungal target cells replicate in medium containing only extracellular ions, glucose, thiamine, and a single nitrogen source such as asparagine $(5,6)$. This report deals with the importance of L-arginine as a necessary substrate for macrophage fungistatic action.

\section{Methods}

Cell culture media. All experiments were performed with media prepared in the laboratory. Dulbecco's modified Eagle's medium (DME) (7) was constructed with stock solutions of the salts, vitamins (Gibco, Grand Island, NY), individual solutions of all of the essential and nonessential amino acids (Sigma Chemical Co., St. Louis, MO), and individual solutions of the other additives at the concentrations given: $25 \mathrm{mM}$ D-glucose, $1 \mathrm{mM}$ sodium pyruvate, $100 \mathrm{U} / \mathrm{ml}$ penicillin $\mathrm{G}, 10$ $\mu \mathrm{g} / \mathrm{ml}$ gentamicin, $25 \mathrm{mM} 3-(N$-morpholino) propane sulfonic acid (MOPS) buffer, pH 7.4. Iron, prepared from pure iron wire according to Cartwright (8), was added as the ferric chloride salt. Bicarbonate concentration was reduced to $24 \mathrm{mM}$ (44 mM in the original DME recipe [7]) so that at a $\mathrm{PCO}_{2}$ of 40 torr an alkaline $\mathrm{pH}$ would not inhibit the replication of Cryptococcus neoformans (9). Fetal bovine serum (FBS) (Sterile Systems, Inc., Logan, UT) was dialyzed exhaustively against phosphate-buffered saline (PBS), pH 7.4, using 50,000 mol wt cutoff tubing (Spectrum Medical Industries, Los Angeles, CA) to remove amino acids present in serum (D-FBS).

Animals. 2-mo-old outbred Swiss CD-1 female (Charles River Breeding Laboratories, Inc., Research Triangle Park, NC) mice were used as a source of peritoneal macrophages. Mice received one of three treatments: $1.0 \mathrm{ml} \mathrm{10 \%}$ proteose peptone i.p. (Difco Laboratories, Inc., Detroit, MI) $3 \mathrm{~d}$ before harvest (stimulated macrophages); $10^{7}$ colony-

1. Abbreviations used in this paper: CM, cytotoxic macrophage(s); D-FBS, dialyzed fetal bovine serum. 
forming units Mycobacterium bovis, strain BCG, Phipps, i.p. 3 wk before harvest and $1.0 \mathrm{ml}$ of peptone i.p. $3 \mathrm{~d}$ before harvest (CM); or no treatment before harvest (resident macrophages) of peritoneal exudate cells.

Macrophage cultures. Four million peritoneal cells were plated in 16-mm diam culture wells (Costar, Cambridge, MA) in DME without serum and were allowed to adhere at $37^{\circ} \mathrm{C}$ under $5 \% \mathrm{CO}_{2}$ for $1 \mathrm{~h}$. Nonadherent cells were removed by rinsing with PBS. This process was repeated with a second seeding of peritoneal cells to produce a confluent macrophage monolayer which was essential for inhibition of cryptococcal cell growth (2). Cultures prepared in this way contained $>90 \%$ mononuclear cells (Giemsa staining) which were actively phagocytic when incubated with heat-killed Candida albicans. Unless stated otherwise, mononuclear phagocyte cultures were immediately challenged with fungi in DME containing additives as described below.

Microorganisms. A clone of Cryptococcus neoformans (serotype A), designated H99/C3D, was isolated from a strain obtained from human cerebrospinal fluid (10). This clone was used because its generation time ( $\sim 3 \mathrm{~h}$ under the culture conditions used) is not affected by elevated $\mathrm{CO}_{2}$ concentration, thereby eliminating a potential confounding variable in measuring the effect of macrophages on fungal cell growth rate (9). The $C$. neoformans clone is narrowly encapsulated on India ink examination. It is phenol oxidase positive, and secretes immunoreactive capsular polysaccharide into the medium (9). It does not produce chronic meningitis in cortisone-treated rabbits (9). Cells were maintained in suspension culture in DME in small culture flasks (25- $\mathrm{cm}^{2}$, Falcon Labware, Oxnard, CA). Log-phase yeasts were washed with PBS by centrifugation $(4,000 \mathrm{~g})$ three times and were resuspended in culture medium at $1 \times 10^{5}$ cells/ml for addition to macrophages. Then $0.5 \mathrm{ml}$ was added to each $16-\mathrm{mm}$ diam culture well.

Mycobacterium bovis, strain BCG, Phipps, was obtained from the Trudeau Institute, Saranac Lake, NY, courtesy of Donald Auclair. A pure culture was grown submerged for $10 \mathrm{~d}$ in Middlebrook 7H9 medium (Difco Laboratories) containing $0.5 \mathrm{ml}$ of Tween 80 per liter plus albumin-dextrose-catalase enrichment. Cultures were maintained in $8 \% \mathrm{CO}_{2}$ at $35^{\circ} \mathrm{C}$ and swirled daily. Late log-phase cells $\left(10^{8}\right.$ to $10^{9} / \mathrm{ml}$ ) were stored at $-85^{\circ} \mathrm{C}$. Culture purity was confirmed by subculturing on chocolate agar and Sabouraud's agar (Difco Laboratories). Quantitative plate counts of mycobacteria were done on Middlebrook 7H10 agar plates with OADC enrichment (Difco Laboratories).

Fungistasis measurements. Details of the macrophage fungistasis assay have been published $(1,2)$. Macrophage-cryptococci cocultures in various media were incubated for $24 \mathrm{~h}$. Then the number of cryptococci was determined by electronic cell counting (Coulter $\mathbf{Z B}_{1}$, Coulter Electronics, Inc., Hialeah, FL) after lysis of phagocytes with $0.9 \%$ (final concentration) sodium dodecyl sulfate. Fungi were killed with hypochlorite prior to counting (1). Experiments employing quantitative plate counts and hemocytometer counts showed excellent correlation with electronic cell counts for enumeration of cryptococci (1). Results of macrophage fungistasis were expressed in two ways. First, data from cell counts were plotted directly on semilog coordinates. Secondly, fungistasis was expressed as the difference between growth in cryptococci alone cultures and macrophage plus cryptococci cocultures. This difference was calculated by: Fungistasis $=\log _{2}$ (fungi alone cultures) - $\log _{2}$ (macrophage plus fungi cultures) after $24 \mathrm{~h}$ of culture. This expression was chosen because the process being inhibited is cell doubling, a logarithmic function to the base 2 . The replication of H99/C3D cryptococci in DME is extremely constant, being between 5 and $6 \log _{2}$ by $24 \mathrm{~h}$ after an initial seeding of $5 \times 10^{4} \mathrm{cells} / \mathrm{ml}$. Hence, the number of replications inhibited by macrophages can be calculated from the $\log _{2}$ difference. Because the initial cell density was constant throughout all experiments $\left(5 \times 10^{4} / \mathrm{ml}\right)$, this value was not included in the calculations.

Reagents. Unless stated, these were obtained from Sigma Chemical Co. Methylated arginine derivatives were from Calbiochem, San Diego, CA. Gamma interferon (IFN $\gamma$ ) and tumor necrosis factor (TNF) were from Genentech, Inc., South San Francisco, CA. Limulus amebocyte lysate was from Panmed Inc., Three Oaks, MI.

\section{Results}

Replication of cryptococci in amino acid deficient media. The nutritional requirements for replication of Cryptococcus neoformans have been determined $(5,6)$. These include a group of essential inorganic ions, a carbon source, a nitrogen source, and one vitamin (thiamine). Chaskes and Tyndall (5) showed that for the phenotypic expression of two virulence factors, phenol oxidase activity and heteropolysaccharide capsule, a salt solution containing glutamine/glycine/asparagine as nitrogen source, glucose to supply carbon, and thiamine were sufficient. Amino acid-free DME was prepared and glutamine/glycine/asparagine were added. This medium supported the replication of cryptococci at the same rate as complete DME irrespective of whether cryptococci had previously been maintained in complete DME or the tri-amino acid DME. This latter medium was used to examine the amino acid requirement(s) for macrophage fungistasis since the replication rate of target cells was independent of the additional essential and nonessential amino acids in DME.

L-Arginine is required for macrophage fungistasis. As reported previously CM had fungistatic capability in D-FBS DME (2); however, when challenged with cryptococci in D-FBS tri-amino acid DME, these same macrophages were unable to inhibit $C$. neoformans replication (Fig. 1). Failure of $\mathrm{CM}$ fungistasis under these conditions was not due to loss of phagocyte viability because $>95 \%$ of $\mathrm{CM}$ excluded trypan blue after a 2-d incubation. Moreover, these macrophages engulfed opsonized $C$. neoformans H99/C3D cells in a standard phagocytosis assay utilizing radiolabeled organisms (9). Changes in $\mathrm{pH}$ of the tri-amino acid DME were measured because the buffering capacity of this medium may have been inadequate for lactic acid production by macrophages. However, the differences between medium $\mathrm{pH}$ of D-FBS DME vs. D-FBS tri-amino acid DME after 24 (7.15 and 7.10, respectively) and 48 (6.8 and 6.9, respectively) $h$ of culture were trivial. Since tri-amino acid DME contained asparagine, which is not present in complete DME, failure of fungistasis could have been due to an inhibitory effect of $5.0 \mathrm{mM}$ asparagine on CM. However, this seemed unlikely because $5.0 \mathrm{mM}$ L-asparagine added to D-FBS DME did not inhibit CM-mediated fungiastasis.

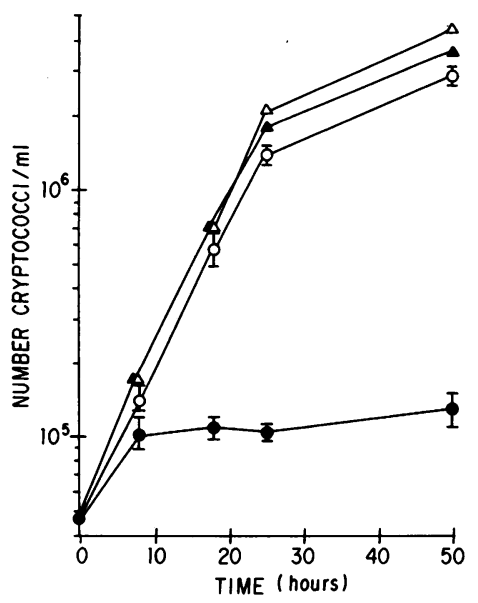

Figure 1. Macrophage fungistasis requires amino acids. Approximately 5 $\times 10^{4}$ cryptococci were added to $\mathrm{CM}$ at time zero. Fungal cell counts were made at the times shown thereafter. $(\bullet, \Delta)$ Macrophage plus cryptococci cultures and cryptococci alone cultures respectively, run in DME plus $10 \%$ D-FBS. (0, $\triangle)$ Macrophage plus cryptococci and cryptococci alone cultures respectively, run in tri-amino acid DME plus $10 \%$ D-FBS. All media contained endotoxin, 10

$\mathrm{ng} / \mathrm{ml}$. Data points are the means \pm SEM (macrophage plus cryptococci triplicate cocultures) or cell counts from single cultures (cryptococci alone). 
In a series of add-back experiments the tri-amino acid DME was reconstituted with the essential and nonessential amino acids at the concentrations present in DME (7). Except for L-arginine, addition of all amino acids singly or in combination, failed to restore any significant fungistatic capability. Addition of $0.5 \mathrm{mM}$ L-arginine to D-FBS tri-amino acid DME led to complete fungistasis equal to that obtained in D-FBS complete DME. Since the single critical amino acid for macrophage fungistasis was L-arginine, further experiments were performed in DME containing all nutrients but L-arginine.

Compounds used as substrate for CM-mediated fungistasis. The results of testing a number of compounds for their potential ability to support $\mathrm{CM}$ fungistatic action when added to DME without L-arginine are shown in Fig. 2. Only two compounds, L-arginine methylester and L-homoarginine, in addition to L-arginine sufficed. L-Arginine methylester may be hydrolyzed to L-arginine by macrophage esterases. L-Homoarginine is a naturally occurring amino acid in plants and is found in high concentrations in the seeds of Lathyrus species (11). Its biological role may be for storage of utilizable nitrogen in the form of the nitrogen-rich guanido group for use during germination (12). L-Homoarginine has not been found in mammals. When arginase was added to macrophage-cryptococci cocultures containing L-arginine, fungistasis was blocked. This finding suggested that ornithine and/or urea are not substrates for fungistatic activity. Other naturally occurring guanido compounds as well as nonamino acid guanido derivatives all failed to support CM fungistasis. The products of L-arginine and L-ornithine metabolism via the decarboxylation pathways, which regulate growth in various species, putrescine, spermidine, and canavanine, were inactive. Likewise, the intermediates of the urea cycle alone or in various combinations (not shown) completely lacked activity. Inability to support CM-mediated fungistasis may occur because of poor penetration of the potential substrates into macrophages. Ability to inhibit carbon-14 labeled L-arginine transport in CM was determined as an indirect measure of penetration of many of the compounds listed in Fig. 2 (Granger, D. L., unpublished data). Cationic amino acids (L-lysine, L-ornithine, L-homoarginine) strongly inhibited L-arginine transport. Zwitter ionic and anionic amino acids were poor inhibitors of transport. The other guanido compounds listed in Fig. 2 did not inhibit L-arginine transport, suggesting they may not enter the phagocytes. However, this analysis does not exclude the possibility that transport of these compounds occurs by another route. It is clear that L-arginine, L-homoarginine, L-lysine, and L-ornithine enter $C M$ via a common carrier. But only $L$-arginine and L-homoarginine support CM-mediated fungistasis. If $C M$ were preincubated for $2 \mathrm{~h}$ in DME containing L-arginine and then cocultured with cryptococci in D-FBS DME without arginine, fungistasis did not occur (not shown). This result argues against the possibility that L-arginine functions as a macrophage activator (i.e., like endotoxin).

Concentration of $L$-arginine required for macrophage fungistasis. The concentration dependence on L-arginine and L-homoarginine for CM fungistatic activity showed similar doseresponse curves (Fig. 3). Maximal effect occurred by $200 \mu \mathrm{M}$ for a 24-h assay. The concentration of L-arginine in Eagle's amino acid mixture which is used in many cell culture media formulations is $\sim 400 \mu \mathrm{M}$. Consequently for long-term in vitro antimicrobial assays, it is possible that the supply of L-arginine may become limiting for cytotoxicity. Substrate deple-

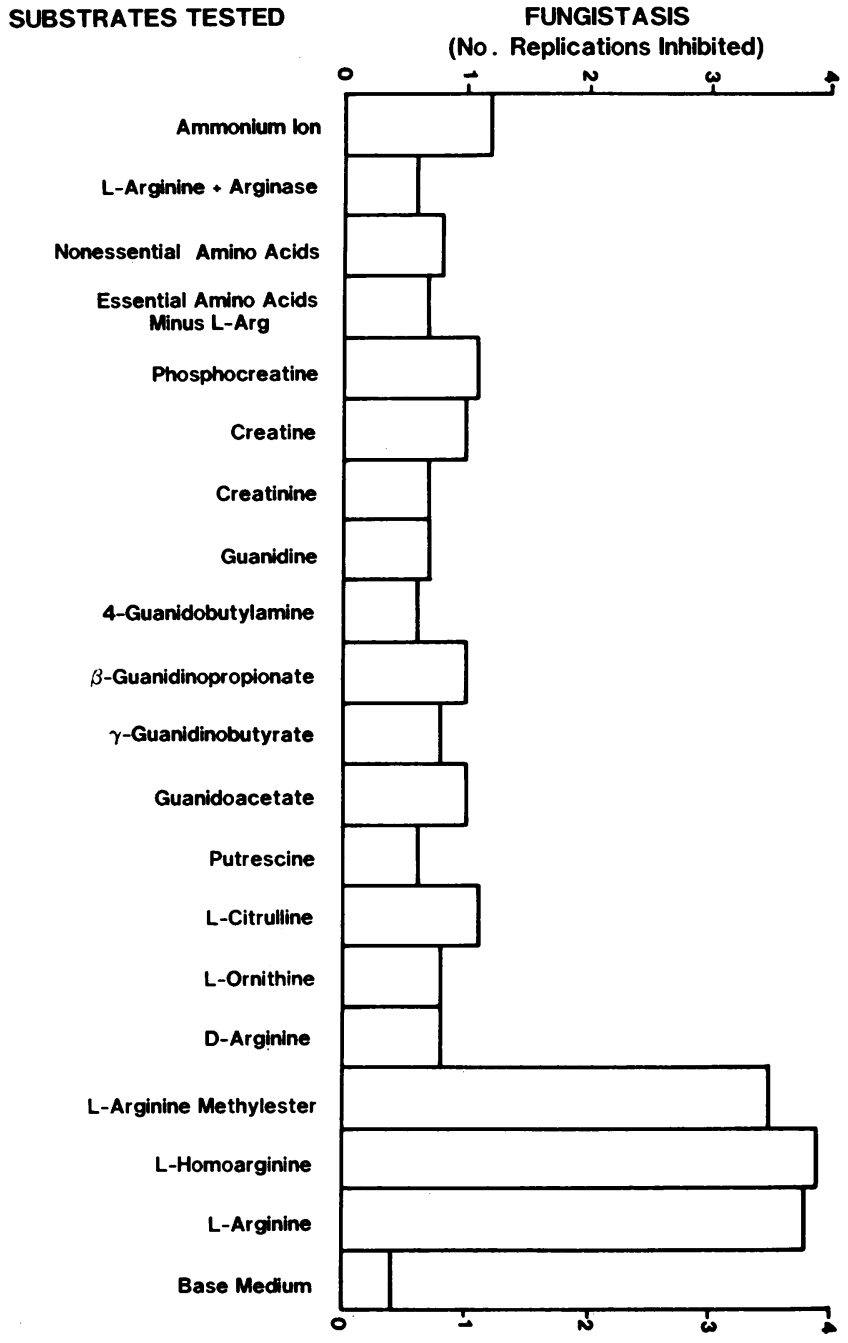

Figure 2. Compounds tested for their capability of supporting macrophage fungistasis in place of $\mathrm{L}$-arginine. $\mathrm{CM}$ fungistasis assays like that shown in Fig. 1 were run in DME minus L-arginine with 10\% D-FBS and $10 \mathrm{ng} / \mathrm{ml}$ endotoxin (base medium) with the additives shown at $0.5 \mathrm{mM}$. After $24 \mathrm{~h}$ of incubation cryptococci were counted and fungistasis was calculated as the difference: ( $\log _{2}$ cryptococci alone cultures) minus ( $\log _{2}$ macrophage + cryptococci cultures), which is the number of replications inhibited. Data are means of duplicate or triplicate cultures and are compiled from five separate experiments. Arginase (bovine liver, Sigma Chemical Co.) concentration was $10 \mathrm{U} / \mathrm{ml}+50 \mu \mathrm{M} \mathrm{MnCl}$. Nonessential amino acids (Ala, Asn, Asp, Gly, Pro, Ser, Glu) obtained commercially (Gibco) were diluted 1:50. Essential amino acids were at the final concentrations for DME (7). None of the additives without CM decreased the replication rate of cryptococci. None of the additives was toxic for $\mathrm{CM}$ as determined by phase contrast microscopy and trypan blue exclusion.

tion is an important consideration because macrophages, which secrete arginase into their environment (13), may additionally deplete L-arginine. This was shown when exogenous arginase was added (Fig. 2). The stereoisomer, D-arginine, was a relatively effective inhibitor of carbon-14-labeled L-arginine transport (Granger, D. L., unpublished data). This suggested that $D$-arginine enters $C M$ via the cationic amino acid carrier, albeit less efficiently than L-arginine. Yet over a wide concen- 


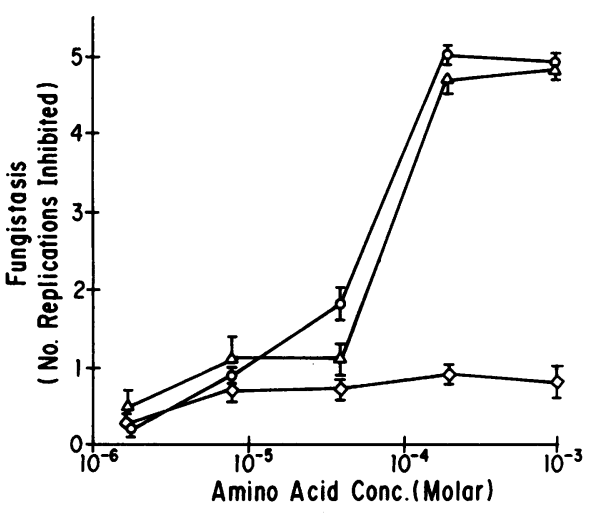

Figure 3. Dose-response curves of amino acid-dependent CM fungistasis. Fungistasis assays were done in DME without L-arginine plus $10 \% \mathrm{D}-\mathrm{FBS}$ and $10 \mathrm{ng} / \mathrm{ml}$ endotoxin (base medium). Fungistasis was calculated as explained in Fig. 2 and Methods. Additives to base medium were L-arginine (0), L-homoarginine $(\Delta)$, and D-arginine $(\diamond)$ at the concentrations shown. Values are means \pm SEM of triplicate cultures. Fungistasis for base medium without additives was $0.5 \pm 0.2$ replications inhibited. None of the additives inhibited cryptococcal replication or was toxic for $\mathrm{CM}$.

tration range D-arginine was incapable of supporting $\mathrm{CM}$ fungistasis. This type of specificity for L-arginine indicated utilization by an enzymatic process.

Relationship to macrophage activation and known activators of macrophage antimicrobial action. Macrophages must be activated to express fungistasis (1). This was also the case for the L-arginine-dependent system (Fig. 4). The relatively increased fungistatic action of BCG/peptone macrophages (CM) without arginine compared with that of peptone or resident macrophages without arginine may be due to metabolism of endogenous amino acid in fully activated cells. Not shown are

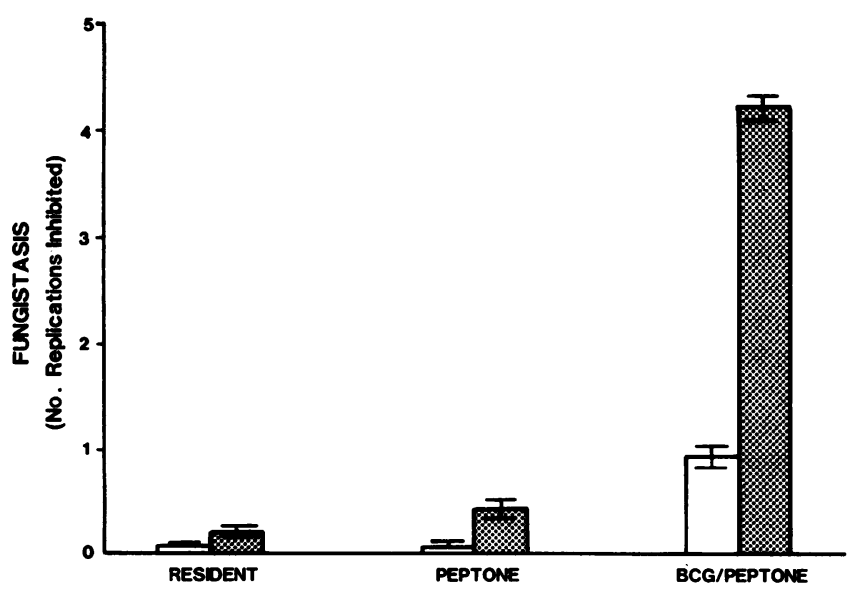

Figure 4. Macrophages must be activated to express L-arginine-dependent fungistasis. Fungistasis assays were done in DME - $\mathrm{L}$-arginine $+10 \%$ D-FBS and endotoxin, $10 \mathrm{ng} / \mathrm{ml}$ (empty bars) or the same medium plus $0.5 \mathrm{mM}$ L-arginine (stippled bars). Resident macrophages were from normal mice without pretreatment. To produce confluent monolayers three macrophage-adherence steps were performed. Peptone macrophages were from mice injected with $1 \mathrm{ml}$ of $10 \%$ peptone $3 \mathrm{~d}$ before sacrifice. Monolayers were from two adherence steps. Activated macrophage (BCG/peptone) cultures were set up as usual. Data are from three separate experiments. Values are means \pm SEM of duplicate cultures. results of adding increasing concentrations of $L$-arginine (up to $5 \mathrm{mM}$ ) to resident or peptone macrophages, which did not increase fungistatic capability.

We have reported that a macromolecular fraction of normal dialyzed serum (D-FBS) is required for CM-mediated fungistasis (2). The relationship of this requirement to the L-arginine requirement is shown in Fig. 5. Without D-FBS the standard L-arginine concentration at $0.5 \mathrm{mM}$ failed to support $\mathrm{CM}$ fungistasis. Increasing D-FBS concentration in the absence of $\mathrm{L}$-arginine showed a minor enhancement of fungistasis. We questioned whether at high serum concentration, proteolysis by macrophage enzymes might have yielded sufficient amino acid to supply the L-arginine-dependent mechanism. Apparently, this was not the case because $40 \%$ D-FBS did not restore significant fungistatic activity to $\mathrm{CM}$ in arginine-free medium.

Endotoxin, IFN $\gamma$, and TNF, enhance macrophage cytotoxicity $(14,15)$. These mediators were tested on BCG/peptone macrophages in medium without $\mathrm{L}$-arginine. Table $\mathrm{I}$ shows that these activators did not replace $\mathrm{L}$-arginine for macrophage fungistatic action. The effect of $\mathrm{L}$-arginine was not due to contaminating endotoxin in the stock solution. This solution did not cause gelation of Limulus amebocyte lysate in an assay sensitive to $<100 \mathrm{pg} / \mathrm{ml}$ standard endotoxin. Furthermore addition of endotoxin without $\mathrm{L}$-arginine did not restore macrophage fungistatic activity. These results are consistent with the notion that the regulatory molecules of activation induce a differentiation state in the macrophage which allows for the metabolic consumption of L-arginine as a substrate for antimicrobial product(s). Thus, the role of $\mathrm{L}$-arginine would be viewed not as a regulatory signal, but rather, as a fuel for bulk consumption to generate cytotoxic effector molecules. It should be noted that IFN $\gamma$ and TNF, which possess antiviral activity, had no direct fungistatic effect at the concentrations tested.

L-Arginine analogues inhibit macrophage fungistasis. Methylated derivatives of $L$-arginine inhibit the ability of macrophages to injure neoplastic cells $(3,4)$. Three of these natu-

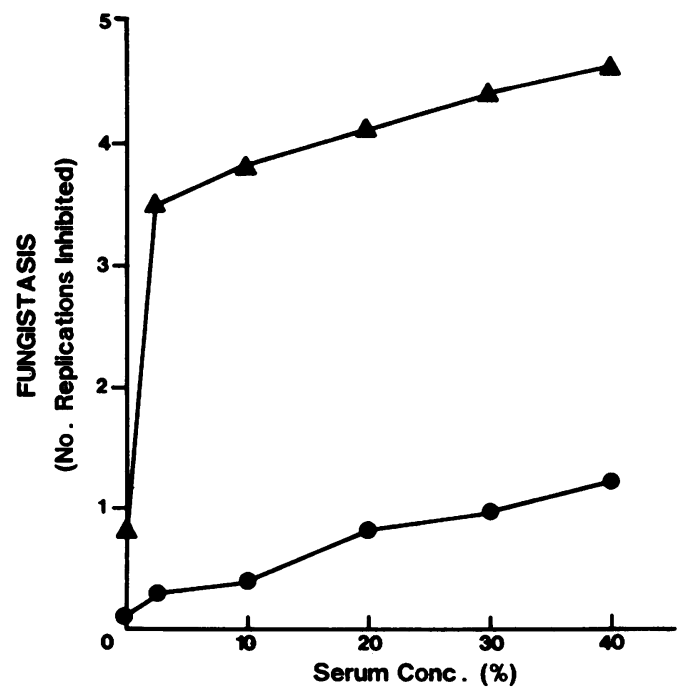

Figure 5. L-Arginine-dependent macrophage fungistasis requires serum. Fungistasis assays were performed with $\mathrm{CM}$ in DME and 10 $\mathrm{ng} / \mathrm{ml}$ endotoxin with ( $\Delta$ ) or without ( 0 ) $0.5 \mathrm{mM} \mathrm{L}$-arginine. Dialyzed FBS was added at time zero at the concentrations shown. Values are the means of duplicate cultures. 
Table I. Effect of Macrophage Activators on L-Argininedependent fungistasis

\begin{tabular}{rccc}
\hline Endotoxin & Mediator & $\begin{array}{c}\text { L-Arginine } \\
(0.5 \mathrm{mM})\end{array}$ & Fungistasis $^{*}$ \\
\hline$n g / m l$ & $100 \mathrm{U} / \mathrm{ml}$ & & \\
0 & - & - & 1.8 \\
0 & - & + & 4.1 \\
10 & - & - & 1.6 \\
10 & - & + & 5.4 \\
100 & - & - & 1.5 \\
100 & - & - & 5.4 \\
0 & IFN $\gamma$ & - & 1.0 \\
10 & IFN $\gamma$ & + & 1.3 \\
10 & IFN $\gamma$ & - & 5.6 \\
0 & TNF & - & 1.2 \\
10 & TNF & + & 1.2 \\
10 & TNF & - & 4.5 \\
0 & IFN $\gamma+$ TNF & - & 1.0 \\
10 & IFN $\gamma+$ TNF & + & 1.1 \\
10 & IFN $\gamma+$ TNF & & 5.0 \\
& & &
\end{tabular}

Results compiled from three separate experiments. Macrophages were from BCG/peptone-treated mice. Medium contained $10 \%$ D-FBS and was negative for endotoxin by the Limulus amebocyte lysate gelation assay.

* Endotoxin up to $100 \mu \mathrm{g} / \mathrm{ml}$ did not promote macrophage fungistasis in the absence of $\mathrm{L}$-arginine.

${ }^{\ddagger}$ IFN $\gamma$ was the murine recombinant molecule. TNF was the murine recombinant molecule.

${ }^{8}$ Fungistasis $=\log _{2}$ cryptococci alone cultures minus $\log _{2}$ macrophages + cryptococci cultures (no. of replications inhibited). Values are means of duplicate or triplicate cultures. No additive inhibited cryptococcal replication without macrophages.

rally occurring derivatives were tested for their ability to inhibit macrophage fungistasis in the presence of $0.5 \mathrm{mM} \mathrm{L-argi-}$ nine (Fig. $6 \mathrm{~A}$ ). The results show a rank order of their inhibitory potency for macrophages: $N^{\mathrm{G}}$-monomethyl-L-arginine $>N^{\mathrm{G}} N^{\mathrm{G}}$-dimethyl-L-arginine (asymmetric) $>N^{\mathrm{G}} N^{1 \mathrm{G}}$-dimethyl-L-arginine (symmetric). None of the three compounds directly inhibited replication of cryptococci up to $1.0 \mathrm{mM}$. The most potent inhibitor, monomethyl-L-arginine, was studied further. The dose-response curve for inhibition by $N^{\mathrm{G}}$-monomethyl-L-arginine is shown in Fig. $6 \mathrm{~B}$. With $0.5 \mathrm{mM} \mathrm{L}$-arginine present, $10 \mu \mathrm{M} N^{\mathrm{G}}$ monomethyl-L-arginine was highly inhibitory. Again, the methylated amino acid (concentration up to $1.0 \mathrm{mM}$ ) had no inhibitory effect for fungi alone. If the structural analogue of L-arginine is a competitive inhibitor of CM fungistasis, increasing substrate concentration should overcome a constant amount of inhibitor. Fig. $6 C$ shows that increasing L-arginine to $3.5 \mathrm{mM}$ overcame the inhibition caused by $30 \mu \mathrm{M} \mathrm{N} N^{\mathrm{G}}$-monomethyl-L-arginine. Preincubation experiments showed that the replacement of medium containing $N^{\mathrm{G}}$-monomethyl-L-arginine with medium containing L-arginine at the time of challenge with cryptococci restored CMmediated fungistasis (Table II). This observation is consistent with competitive inhibition by $N^{\mathrm{G}}$-monomethyl-L-arginine.

L-Arginine fungistasis data with and without $N^{\mathrm{G}}$-mono-
methyl-L-arginine inhibition were expressed by double reciprocal plotting of $1 /$ substrate concentration against 1 /fungistasis values as in enzyme kinetics analysis (Fig. $6 D$ ). This could be justified because the biological effects being measured are rates (of fungal replication or the inhibition thereof). The results show classical competitive inhibition by $N^{\mathrm{G}}$-monomethyl-L-arginine with a common $y$-intercept $\left(1 / V_{\max }\right)$ and a shift in the $x$-intercept $\left(-1 / K_{\mathrm{m}}\right) . V_{\max }$ equals 6.7 , which is the theoretical maximal number of replications which could be inhibited by CM during the 24-h assay. This calculated value is never achieved experimentally because: $(a)$ there is an initial 4-6 $\mathrm{h}$ lag phase when cryptococci replicate freely before macrophages turn off fungal reproduction (1), and $(b)$ the cryptococci enter stationary phase at $\sim 18 \mathrm{~h}$ into the assay. The $K_{\mathrm{m}}$ for L-arginine equals $124 \mu \mathrm{M}$. The $K_{\mathrm{i}}$ for $N^{\mathrm{G}}$-monomethyl-Larginine equals $1.5 \mu \mathrm{M} .{ }^{2}$ Inhibition of carbon-14-labeled L-arginine transport into $\mathrm{CM}$ by $N^{\mathrm{G}}$-monomethyl-L-arginine was measured (Granger, D. L., unpublished data). The methylated amino acid was a poor inhibitor of transport $\left(K_{\mathrm{i}}=500 \mu \mathrm{M}\right)$. These results strongly suggest that $N^{\mathrm{G}}$-monomethyl-L-arginine competes with L-arginine at the active site of a macrophage enzyme which is required for fungistatic action.

\section{Discussion}

Rich (16) emphasized that a microbiostatic mechanism operating in the tissues against facultative intracellular pathogens must be a critical factor in the host-parasite relationship. Clinical remissions of tuberculosis were attributed to the "restraining power" possessed by mononuclear phagocytes: exacerbations to the loss of this function. Modern work on macrophage and neutrophil antimicrobial function has focused primarily on killing mechanisms (17-21). Mechanisms that have been implicated in killing such as the respiratory burst (22), the synthesis of cationic proteins (23), and the elaboration of microbiocidal proteins (19) cannot be demonstrated to account for microbiostasis without killing in vitro. Thus, the possibility exists that an additional cytotoxicity mechanism can be used by macrophages to inhibit the replication of microorganisms. Such a mechanism could be critical to host defense in the face of pathogenic microbes which resist killing mechanisms, enabling them to survive in tissues for long periods.

The biostatic property of activated macrophages was demonstrated in vitro during investigations on their antitumor effects (24). Krahenbuhl and Remington showed that macrophages totally abort the $S$ phase of replicating neoplastic cells without killing them $(25,26)$. These static tumor cells have metabolic aberrations which may be unique to macrophageinduced injury and not merely the result of a common pathway of cell injury due to diverse cytotoxic insults. For example, mitochondrial electron transport is inhibited at the flavoprotein dehydrogenases (27-29). These inhibitions are accompanied by iron loss from tumor cells (30). Recent evidence points to iron-sulfur cluster prosthetic groups within these enzymes as the molecular targets of macrophage-induced injury (31).

The ultimate proof of the existence of a mechanism in macrophages that could account for these phenomena was provided by Hibbs et al. (4), who discovered that L-arginine

2. $K_{\mathrm{i}}=K_{\mathrm{m}}[I] /\left(s V_{\max }-K_{\mathrm{m}}\right)$, where $[I]=$ inhibitor concentration; and $s$ = slope with inhibitor present (Fig. $6 \mathrm{D}, \bullet)$. 

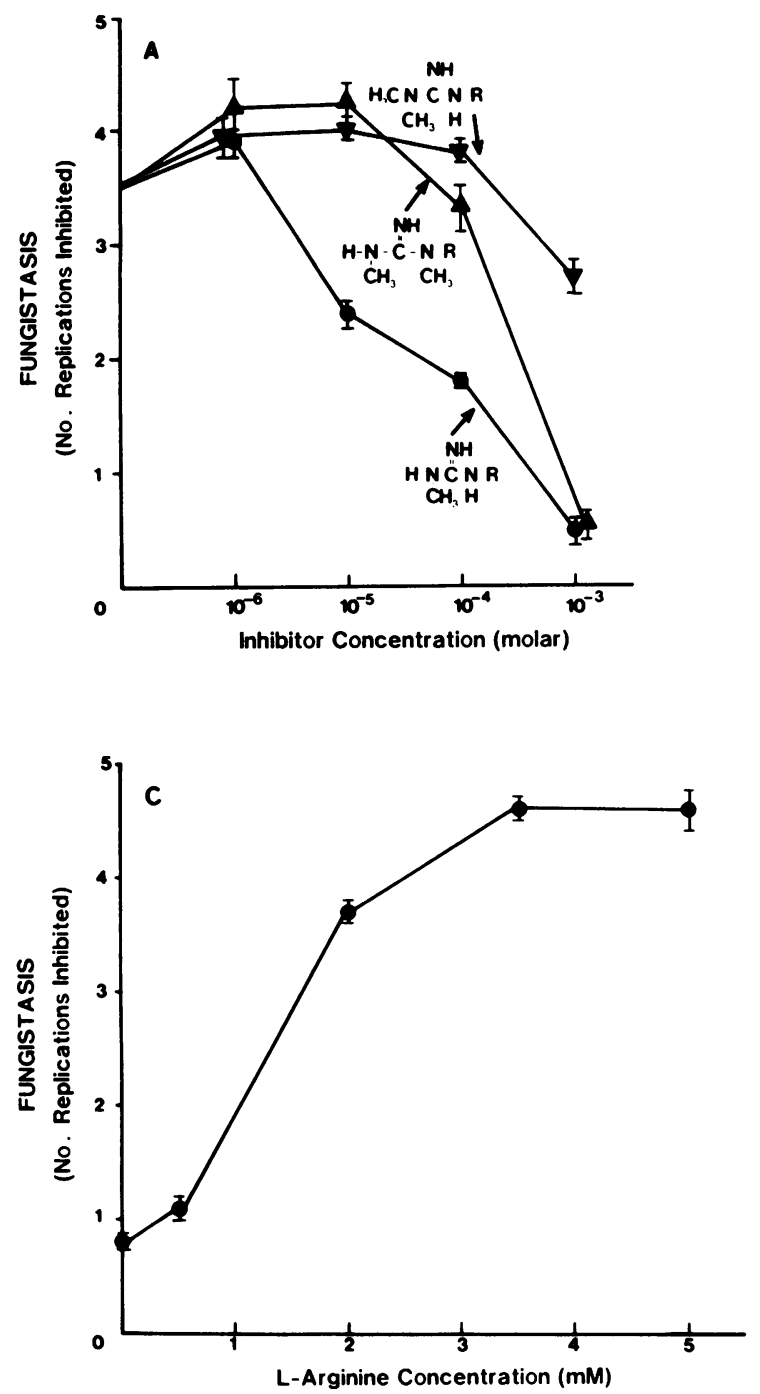

Figure 6. Inhibition of L-arginine-dependent $\mathrm{CM}$ fungistasis by $\mathrm{N}$ methylated L-arginine analogues. $(A)$ Fungistasis assays were run in DME with $0.5 \mathrm{mM}$ L-arginine plus 10\% D-FBS and endotoxin, 10 $\mathrm{ng} / \mathrm{ml} \pm N^{\mathrm{G}}$-monomethyl-L-arginine (๑), $N^{\mathrm{G}} N^{\mathrm{G}}$-dimethyl-L-arginine $(\Delta)$, or $N^{1 G} N^{G}$-dimethyl-L-arginine ( $\left.\nabla\right)$ at the concentrations shown. Values are means \pm SEM of triplicate cultures. The inhibitors were not toxic for CM up to $1.0 \mathrm{mM}$. (B) Fungistasis assays were run in DME with $0.5 \mathrm{mM}$ L-arginine, $10 \%$ D-FBS, and endotoxin $10 \mathrm{ng} / \mathrm{ml}$ and $N^{\mathrm{G}}$-monomethyl-L-arginine at the concentrations shown. Points are means \pm SEM of triplicate cultures. $(C)$ Conditions were DME

was required to induce the metabolic changes in tumor cells characteristic of macrophage-induced injury. $N^{\mathbf{G}}$ monomethyl-L-arginine specifically inhibited this process (4). It was further shown that the products of L-arginine metabolism were nitrite and citrulline (3). Earlier, Stuehr and Marletta (32) had shown that murine activated macrophages produced nitrate in vivo and in vitro (32). This work in turn stemmed from recent literature demonstrating that nitrate biosynthesis occurred in mammals $(33,34)$. It had previously been thought that the three sole sources of urinary nitrite and nitrate were the diet, from the atmosphere, and production through intestinal bacterial metabolism (35).
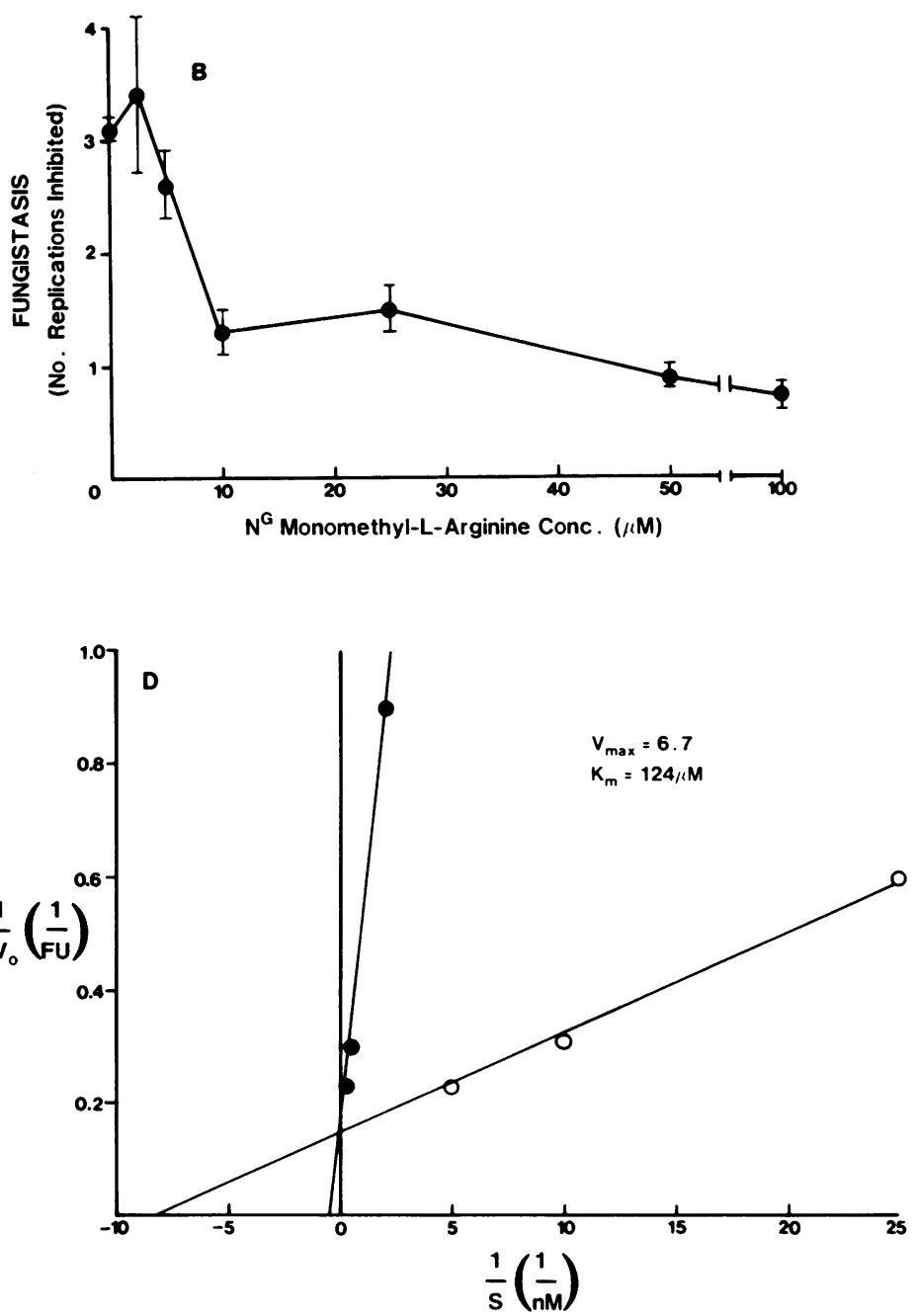

with $10 \%$ D-FBS and 10 nanograms/ml endotoxin with $30 \mu \mathrm{M} N^{\mathrm{G}}$. monomethyl-L-arginine and the concentrations of L-arginine as shown. Values are means \pm SEM of triplicate cultures. $(D)$ Double reciprocal plots of $\mathrm{CM}$ fungistasis (1/FU) vs. L-arginine concentration (1/S) without (O), or with (๑), $30 \mathrm{mM} N^{\mathrm{G}}$-monomethyl-L-arginine. FU = number of replications inhibited. $V_{\max }=1 / y$-intercept; $K_{\mathrm{m}}$ $=(\mathrm{s})\left(V_{\max }\right)$, where $s=$ slope of line without inhibitor $(0) . K_{\mathrm{i}}$ for $N^{\mathrm{G}}$ monomethyl-L-arginine $=1.5 \mu \mathrm{M}$ (see text). Values calculated from the means of triplicate cultures at each substrate or substrate plus inhibitor concentration(s).

In this report we have shown that L-arginine is linked to a microbiostatic mechanism which can be used to inhibit the replication of a pathogenic fungus. This is presumably due to the same biochemical process first revealed in toxicology studies (32-34) and defined by Hibbs et al. $(3,4)$ in macrophagemediated tumor cell injury. Further experimentation will reveal whether L-arginine metabolism will be linked to inhibition of protozoal and bacterial pathogens. It is relevant that the effect of this mechanism may not lead to target cell death. Consequently, it is possible that this process may be used as a macrophage effector function to regulate cell growth during embryogenesis, immune responses, or in immunosurveillance. 
Table II. Inhibition of Macrophage-mediated Fungistasis by $N^{G}$-Monomethyl-L-Arginine is Reversible

\begin{tabular}{|c|c|c|}
\hline $\begin{array}{l}\text { Preincubation substrate } \\
\text { or inhibitor* }\end{array}$ & $\begin{array}{l}\text { Assay incubation substrate } \\
\text { or inhibitor* }\end{array}$ & $\begin{array}{l}\text { Fungistasis } \\
\text { (no. of replications } \\
\text { inhibited) }\end{array}$ \\
\hline No additions & L-Arginine & $4.4(4.1-4.7)$ \\
\hline L-Arginine & L-Arginine & $3.8(3.5-3.9)$ \\
\hline $\begin{array}{l}N^{\mathrm{G}} \text {-monomethyl- } \\
\text { L-arginine }\end{array}$ & $\begin{array}{l}N^{G} \text {-monomethyl- } \\
\text { L-arginine }\end{array}$ & 0 \\
\hline $\begin{array}{l}N^{\mathrm{G}} \text {-monomethyl- } \\
\text { L-arginine }\end{array}$ & L-Arginine & $3.9(3.8-4.0)$ \\
\hline L-Arginine & $\begin{array}{l}N^{G} \text {-monomethyl- } \\
\text { L-arginine }\end{array}$ & 0 \\
\hline
\end{tabular}

* L-Arginine concentration was $0.5 \mathrm{mM} . N^{\mathrm{G}}$-monomethyl-L-arginine concentration was $25.0 \mu \mathrm{M}$. Preincubation lasted $2 \mathrm{~h}$. Preincubation medium did not contain serum or endotoxin. Assay incubation lasted $18 \mathrm{~h}$. Assay incubation medium contained 10\% dialyzed FBS and endotoxin, $10 \mathrm{ng} / \mathrm{ml}$.

¥Values are means with ranges in parentheses for triplicate cultures.

All experiments on L-arginine-dependent macrophage fungistasis are consistent with an enzyme-substrate reaction. The $\mathrm{L}$-arginine effect is concentration dependent. It is highly specific for the native amino acid, and the closely related analogues, L-homoarginine and L-arginine methyl ester. Fungistasis is specifically inhibited by $N^{\mathrm{G}}$-monomethyl-L-arginine and this process shows the features of competitive inhibition of an enzyme-substrate reaction. Differences in inhibitor potency relate to alterations in the guanido group of arginine suggesting enzyme attack on this portion of the molecule. An alternative possibility for these findings is that dose requirement, substrate, and inhibitor specificity are occurring at the level of a macrophage membrane carrier for $\mathrm{L}$-arginine. The role of amino acid transport must be addressed to resolve this issue. There is no evidence that arginine acts as a modulator or signal for macrophage activation. Indeed, this possibility seems unlikely. Activating signals are effective in preincubation experiments without having to be present during the cytotoxicity assay. This is not the case for L-arginine-dependent fungistasis. Presumably L-arginine is a chemical fuel that powers the active process of macrophage microbiostasis. The products of L-arginine metabolism that mediate fungistasis are unknown. Nitrite, nitrate, ammonium ion, hydroxylamine, citrulline, or combinations of these potential metabolites in concentrations which could be maximally achieved in the in vitro culture assay (100-500 $\mu \mathrm{M})$ have no inhibitory effect on the replication rate of $C$. neoformans (Granger, D. L., unpublished data). It is possible that oxygen intermediates generated during nitrogen redox reactions could produce fungistasis $(36,37)$.

The dose-response curve for $\mathrm{L}$-arginine is steep in the 100 $\mu \mathrm{M}$ range (Fig. 3 , and $K_{\mathrm{m}}=124 \mu \mathrm{M}$, Fig. $6 \mathrm{D}$ ). This value is important to consider from the standpoint of an in vitro assay where the beginning concentration of $\mathrm{L}$-arginine may be $\sim 400 \mu \mathrm{M}$ (as in DME). It is apparent that under long-term culture conditions the utilization of $\mathrm{L}$-arginine by effector and target cells may reduce substrate concentration below that required for maximal fungistatic activity by $\mathrm{CM}$. In considering in vivo conditions, it may be relevant that the $\mathrm{L}$-arginine concentration in human plasma and other extracellular fluids is in the range of this value, that is $\sim 100 \mu \mathrm{M}$ (38). This might suggest that macrophage microbiostatic function could be regulated in part by altering the $K_{\mathrm{m}}$ for L-arginine metabolism as a rate-limiting step in this process. This could be at the level of transport or enzymatic attack on the arginine molecule itself. It also raises the possibility that failure of the free flow of amino acid to foci of infection could result in immunoincompetence via a mechanism not previously considered. In this regard it is intriguing to recall that one of the pleiotypic effects of interleukin 1 is to induce skeletal muscle proteolysis (39, 40). The released amino acids enter the circulation and are consumed in gluconeogenesis and protein synthesis, for example of immunoglobulins. This response could be the source of $\mathrm{L}$-arginine in the infected, anorexic animal. In protein-calorie malnutrition a suboptimal release of amino acids might be predicted, leading to cell-mediated immunodeficiency.

\section{Acknowledgments}

We thank Donna Ross, Ring Tsai, Ferdo Ong, and Lisa Penning for conscientious technical assistance, and Dr. Brice Weinberg and Dr. Kevin Lee-See for reviewing the manuscript.

This work was supported by National Institutes of Health grant CA-35893-01 and a grant from R. J. Reynolds-Nabisco Industries.

\section{References}

1. Granger, D. L., J. R. Perfect, and D. T. Durack. 1986. Macrophage-mediated fungistasis in vitro: requirements for intracellular and extracellular cytotoxicity. J. Immunol. 136:672-680.

2. Granger, D. L., J. R. Perfect, and D. T. Durack. 1986. Macrophage-mediated fungistasis: requirement for a macromolecular component in serum. J. Immunol. 137:693-701.

3. Hibbs, J. B., Jr., R. R. Taintor, and Z. Vavrin. 1987. Macrophage cytotoxicity: role for $\mathrm{L}$-arginine deiminase and imino nitrogen oxidation to nitrite. Science (Wash. DC.) 235:473-476.

4. Hibbs, J. B., Jr., Z. Vavrin, and R. R. Taintor. 1987. L-Arginine is required for expression of the activated macrophage effector mechanism causing selective metabolic inhibition in target cells. J. Immunol. 238:550-565.

5. Chaskes, S., and R. L. Tyndall. 1975. Pigment production by Cryptococcus neoformans from para- and othro-diphenols: effect of the nitrogen source. J. Clin. Microbiol. 1:509-514.

6. Littman, M. L., and L. E. Zimmerman. 1956. Cryptococcosis. Grune \& Stratton, New York. 105-108.

7. Tissue Culture Standards Committee. 1970. Tissue culture media. In Vitro (Rockville). 6:93-94.

8. Cartwright, G. E. 1968. Diagnostic Laboratory Hematology. 4th edition. Grune \& Stratton, New York. 212.

9. Granger, D. L., J. R. Perfect, and D. T. Durack. 1985. Virulence of Cryptococcus neoformans: regulation of capsule synthesis by carbon dioxide. J. Clin. Invest. 76:508-516.

10. Perfect, J. R., S. D. R. Lang, and D. T. Durack. 1980. Chronic cryptococcal meningitis. Am. J. Pathol. 101:177-193.

11. Bell, E. A. 1962. Associations of ninhydrin-reacting compounds in the seeds of 49 species of Lathyrus. Biochem. J. 83:225-229.

12. Bell, E. A. 1965. Homoarginine, gamma hydroxylarginine and related compounds. In Comparative Biochemistry of Arginine and Derivatives. G. E. W. Wolstenholme and M. P. Cameron, editors. Ciba Foundation Study Group No. 19. Little, Brown \& Co., London. 20-35.

13. Currie, G. A. 1978. Activated macrophages kill tumor cells by releasing arginase. Nature (Lond.). 273:758-759. 
14. Pace, J. L., S. W. Russell, B. A. Torres, H. M. Johnson, and P. W. Gray. 1983. Recombinant mouse gamma interferon induces the priming step in macrophage activation for tumor cell killing. J. Immunol. 130:2011-2016.

15. Carswell, E. A., L. J. Old, R. L. Kassel, S. Green, N. Fiore, and B. Williamson. 1975. An endotoxin-induced serum factor that causes necrosis of tumors. Proc. Natl. Acad. Sci. USA. 72:3666-3670.

16. Rich, A. R. 1951. The mechanism responsible for restricting the increase in the number of bacilli. In The Pathogenesis of Tuberculosis. 2nd edition. C. C Thomas, Springfield, IL. 606-611.

17. Murray, H. W., C. W. Juangbhanich, C. F. Nathan, and Z. A. Cohn. 1979. Macrophage oxygen-dependent antimicrobial activity. II. The role of oxygen intermediates. J. Exp. Med. 150:950-964.

18. Lehrer, R. I., L. G. Ferrari, J. Patterson-Delafield, and T. Sorrell. 1980. Fungicidal activity of rabbit alveolar and peritoneal macrophages against Candida albicans. Infect. Immun. 28:1001-1008.

19. Elsbach, P., and J. Weiss. 1983. A reevaluation of the roles of the $\mathrm{O}_{2}$-dependent and $\mathrm{O}_{2}$-independent microbiocidal systems of phagocytes. Rev. Infect. Dis. 5:843-853.

20. Gabay, J. E., J. M. Heiple, Z. A. Cohn, and C. F. Nathan. 1986. Subcellular location and properties of bactericidal factors from human neutrophils. J. Exp. Med. 164:1407-1421.

21. Bast, R. C., R. P. Cleveland, B. H. Littman, B. Zbar, and H. J. Rapp. 1974. Acquired cellular immunity: extracellular killing of Listeria monocytogenes by a product of immunologically activated macrophages. Cell. Immunol. 10:248-259.

22. Johnston, R. B., C. A. Godzik, and Z. A. Cohn. 1978. Increased superoxide anion production by immunologically activated and chemically elicited macrophages. J. Exp. Med. 148:115-127.

23. Ganz, T., M. E. Selsted, D. Szklarek, S. S. L. Harwig, K. Daher, D. F. Bainton, and R. I. Lehrer. 1985. Defensins: natural peptide antibiotics of human neutrophils. J. Clin. Invest. 76:1427-1435.

24. Evans, R., and P. Alexander. 1976. Mechanisms of extracellular killing of nucleated mammalian cells by macrophages. In Immunobiology of the Macrophage. D. S. Nelson, editor. Academic Press, Inc., New York. 535-576.

25. Krahenbuhl, J. E. 1980. Effects of activated macrophages on tumor target cells in discrete phases of the cell cycle. Cancer Res. 40:4622-4627.

26. Krahenbuhl, J. L., and J. S. Remington. 1980. Cytostatic effects of activated macrophages on tumor target cells: inhibition of cytotoxic action of ARA-C. J. Immunopharmacol. 2:325-348.

27. Granger, D. L., R. R. Taintor, J. L. Cook, and J. B. Hibbs, Jr.
1980. Injury of neoplastic cells by murine macrophages leads to inhibition of mitochondrial respiration. J. Clin. Invest. 65:357-370.

28. Granger, D. L., and A. L. Lehninger. 1982. Sites of inhibition of mitochondrial electron transport in macrophage-injured neoplastic cells. J. Cell. Biol. 95:527-535.

29. Kilbourn, R. G., J. Klostergaard, and G. Lopez-Berestein. 1984. Activated macrophages secrete a soluble factor that inhibits mitochondrial respiration of tumor cells. J. Immunol. 133:2577-2581.

30. Hibbs, J. B., Jr., R. R. Taintor, and Z. Vavrin. 1984. Iron depletion: Possible cause of tumor cell cytotoxicity induced by activated macrophages. Biochem. Biophys. Res. Commun. 123:716-723.

31. Drapier, J. C., and J. B. Hibbs, Jr. 1986. Murine cytotoxic activated macrophages inhibit aconitase in tumor cells: inhibition involves the iron-sulfur prosthetic group and is reversible. J. Clin. Invest. 78:790-797.

32. Stuehr, D. J., and M. A. Marletta. 1985. Mammalian nitrate biosynthesis: mouse macrophages produce nitrite and nitrate in response of Escherichia coli lipopolysaccharide. Proc. Natl. Acad. Sci. USA. 82:7738-7742.

33. Green, L. C., K. Ruiz de Luzuriaga, D. A. Wagner, W. Rand, N. Istfan, V. R. Young, and S. R. Tannenbaum. 1981. Nitrate biosynthesis in man. Proc. Natl. Acad. Sci. USA. 78:7764-7768.

34. Wagner, D. A., V. R. Young, and S. R. Tannenbaum. 1983. Mammalian nitrate biosynthesis: incorporation of ${ }^{15} \mathrm{NH}_{3}$ into nitrate is enhanced by endotoxin treatment. Proc. Natl. Acad. Sci. USA. 80:4518-4521.

35. Green, L. C., S. R. Tannenbaum, and P. G. Goldman. 1981. Nitrate synthesis in the germ-free and conventional rat. Science (Wash. DC). 212:56-58.

36. Dull, B. J., and J. H. Hotchkiss. 1984. Activated oxygen and mammalian nitrate biosynthesis. Carcinogenesis. 5:1161-1164.

37. Saul, R. L., and M. C. Archer. 1984. Oxidation of ammonia and hydroxylamine to nitrate in the rat and in vitro. Carcinogenesis. 5:77-81.

38. Bremer, H. J., M. Duran, J. P. Kamerling, H. Pryzrembel, and S. K. Wadman. 1981. Disturbances of amino acid metabolism: clinical chemistry and diagnosis. Urban \& Schwarzenberg, Baltimore. 203-220.

39. Beisel, W. R. 1977. Magnitude of the host nutritional responses to infection. Am. J. Clin. Nutr. 30:1236-1247.

40. Yang, R. D., L. L. Moldawer, A. Sakamoto. 1983. Leukocyte endogenous mediator alters protein dynamics in rats. Metab. Clin. Exp. 32:654-660. 